\title{
BIOTRANSFORMATION OF COUMARIN DERIVATIVES (1) 7-ALKOXYCOUMARIN O-DEALKYLASE IN LIVER MICROSOMES
}

\author{
Takashi MATSUBARA, Emiko YOSHIHARA, Tsuyoshi IWATA, \\ Yoshihiro TOCHINO and Yoshimi HACHINO* \\ Shionogi Research Laboratories. Shionogi \& Co. Lto.. Fukushima-ku. Osaka 553. Japan \\ - Department of Molecular Physiological Chemistry. Medical School of Osaka University. \\ Kita-ku. Osaka 530. Japan
}

Accepted September 11, 1981

\begin{abstract}
The in vitro metabolic fate of 7 -alkoxycoumarin was studied using liver microsomes. Microsomal enzyme catalyzed dealkylation of 7alkoxycoumarin to 7-hydroxycoumarin in the presence of $\mathrm{NADPH}$ and molecular oxygen as cofactors was found to be one of the metabolic pathways. The metabolite 7-hydroxycoumarin was further metabolized to unidentified metabolite(s) in the presence of NADPH and $\mathrm{O}_{2}$ at a very slow rate, while the formation of the conjugate of 7-hydroxycoumarin with glucuronic acid was observed in the presence of UDPGA. Microsomal 7alkoxycoumarin $\mathrm{O}$-dealkylase activity was altered by the substitution of the alkyl group of the substrate, and the substitutions to either an $O$-propyl or an O-butyl group resulted in a decrease of the enzyme activity. Species differences were observed in the substrate specificity of microsomal $\mathrm{O}$ dealkylation. The $\mathrm{O}$-dealkylase activities in rat liver microsomes were stimulated by pretreatment of the animals with phenobarbital, regardless of the $\mathrm{O}$-alkyl substituent at the 7 position of the coumarin ring. On the other hand, pretreatment with 3-methylcholanthrene or $\beta$-naphthoflavone resulted in marked increase of 0 -deethylation, $\mathrm{O}$-depropylation and $\mathrm{O}$ debutylation activities, but not of $\mathrm{O}$-demethylation activity. Pretreatment of animals with $\beta$-naphthoflavone also resulted in remarkable stimulation of 7-hydroxycoumarin-glucuronide formation by the microsomal enzyme, while the conversion of 7-hydroxycoumarin to unidentified metabolite(s) was activated by the pretreatment of rats with only phenobarbital. The 0 -dealkylation activities in liver microsomes from intact and phenobarbital pretreated rats were inhibited markedly by the addition of hexobarbital to the incubation mixture, but no inhibition was observed with $\alpha$-naphthoflavone. On the other hand, the $\mathrm{O}$-dealkylation activities in microsomes from $\beta$ naphthoflavone-pretreated rats were inhibited remarkably by $\alpha$-naphthoflavone. These results confirmed that several microsomal enzymes, including the cytochrome P-450's and UDP-glucuronyltransferase, participate in the biotransformation of 7-alkoxycoumarin, and these enzymes are regulated differently by inducers.
\end{abstract}

The hepatic microsomal mixed-function oxidase system, containing cytochrome P-450 as a terminal oxidase, functions in oxidative biotransformation of a wide variety of both endogenous and exogenous compounds (13). Recent studies have established the existence of multiple forms of cytochrome $P-450$ in liver microsomes obtained from 
various species of animals (4-10). To clarify the physiological and toxicological relationships between cytochrome P.450 species and their catalytic activities, variations in the metabolism of steroids, drugs and carcinogens have been studied using liver microsomes from various species of animals $(11-15)$.

The 0 -dealkylation reaction of 7-alkoxycoumarin was introduced as a measure of cytochrome P-450-dependent mixedfunction oxidation by Ullrich and Weber (16). and this has been employed widely because sensitive and easy assay (7, 17-23). Recent work by Kamataki et al. (24) indicated marked increase of microsomal $\mathrm{O}$-dealkylase activity towards 7-ethoxy-and 7-propoxycoumarins when animals were pretreated with 3methylcholanthrene or isosafrole. suggesting the usefulness of the $\mathrm{O}$-dealkylation reaction of 7-alkoxycoumarin for detecting alterations of cytochrome P-450 species in microsomal membrane. Meanwhile, investigations on the fate of coumarin and its derivatives in the animal body were carried out by several investigators who observed hydroxylated and lactone-ring cleavaged products and also their conjugates as urinary metabolites (2527). The results indicated that 7-hydroxycoumarin, the dealkylated metabolite of 7-alkoxycoumarin, formed glucuronide and ethereal sulfate $(25,26)$, suggesting the existence of several metabolic pathways for coumarin derivatives in liver.

To further clarify the substrate specificity of cytochrome P-450. we reexamined the assay conditions for 7-alkoxycoumarin $\mathrm{O}$ dealkylase and compared the O-dealkylase activities among liver microsomes from animals in various states. The correlation between $\mathrm{O}$-dealkylation and conjugation reactions was also determined using isolated rat liver microsomes.

\section{MATERIALS AND METHODS}

Animals and their treatments: Nine to
11 week old adult rats of Wistar strain were used exclusively. The rats were kept in an air-conditioned room $\left(25 \pm 1{ }^{\circ} \mathrm{C}, \quad 50-60 \%\right.$ humidity) lighted $12 \mathrm{hr}$ a day (8:00-20:00). and maintained on commercial rat chow (CE-1. Japan Clea, Tokyo) and water ad libitum. Some of the rats were given intraperitoneally phenobarbital in physiological saline or 3-methylcholanthrene for $\beta$ naphthoflavone) in sesame oil once a day for 3 consecutive days at doses of $40 \mathrm{mg} / \mathrm{kg}$ body weight.

The following male adult animals were also used for the experiment: mouse (ICR strain. 10-11 weeks old), guinea pig (Hartly, 300$350 \mathrm{~g}$ ), rabbit (Japanese White, $2.5-3.0 \mathrm{~kg}$ ). Beagle dog $(8-10 \mathrm{~kg})$ and Cynomolgus monkey (Macaca fascicalaris, 4.5-5.0 kg) They were kept under almost similar conditions as shown above.

Preparation of liver microsomes: Nonfasted animals were decapitated one day after the last injection, and the livers were quickly removed. minced in ice-cold $0.154 \mathrm{M}$ $\mathrm{KCl}$ containing $50 \mathrm{mM}$ Tris- $\mathrm{HCl}$ buffer $(\mathrm{pH}$ 7.4), and homogenized in a glass PotterElvehjem type homogenizer with a Teflon pestle. Some of the animals (rabbit, dog and monkey) were killed under ether or pentobarbital anaethesia. The microsomal fraction was isolated by 1 -hr centrifugation at $104,000 \times \mathrm{g}$ of the supernatant resulting from $10-\mathrm{min}$ centrifugation of the homogenate at $15,000 \times \mathrm{g}$. The pellet thus obtained was resuspended in $0.25 \mathrm{M}$ sucrose containing $50 \mathrm{mM}$ Tris- $\mathrm{HCl}$ buffer $(\mathrm{pH} \mathrm{7.4)}$ and used as the microsomal fraction.

Analytical and assay methods: Microsomal protein concentration was determined by the biuret reaction (28) using bovine serum albumin as standard. Microsomal cytochromes were detected by difference spectroscopy using a Shimazu UV-300 spectrophotometer. Cytochrome P-450 was determined according to the method of 
Omura and Sato (29).

Microsomal 7-alkoxycoumarin O-dealkylase activity was determined by the fluorometric measurement of 7-hydroxycolimarin produced in the reaction mixture during the incubation. A typical incubation mixture consisted of microsomes, substrate (100 $\mu \mathrm{g}$, or $0.46-0.57 \mu$ moles) and NADPH generating system $(0.25$ umoles NADP. 2.5 amoles glucose 6 -phosphate and 0.65 I.U. glucose 6-phosphate dehydrogenase) in $1.5 \mathrm{ml}$ of a buffer mixture $(50 \mathrm{mM}$ Tris $-\mathrm{HCl}$ buffer, $\mathrm{pH} 7.4$, containing $150 \mathrm{mM} \mathrm{KCl}$ and $10 \mathrm{mM} \mathrm{MgCl}_{2}$ ). The reaction was started by adding the NADPH-generating system. and mixture was incubated aerobically at $37^{\circ} \mathrm{C}$ for $10 \mathrm{~min}$. The reaction was terminated by immersing the incubation tubes in a boiling water bath for $5 \mathrm{~min}$. After cooling the mixture, $4 \mathrm{ml}$ ether was added to the incubation mixture, and this was shaken mechanically for $10 \mathrm{~min}$. A portion $(1-2 \mathrm{ml})$ of the ether layer was added to $0.5 \mathrm{ml} \mathrm{H} \mathrm{H}_{2} \mathrm{O}$ and warmed to $60-65^{\circ} \mathrm{C}$ to evaporate the ether. Next. $2.5 \mathrm{ml}$ of $0.2 \mathrm{M}$ carbonatebicarbonate buffer ( $\mathrm{pH} \mathrm{10)}$ was added and mixed; then the fluorescence intensity was measured at $455 \mathrm{~nm}$ with an excitation of $370 \mathrm{~nm}$ using a Hitachi fluorescence spectrophotometer, Model 650-10S.

The percent recovery of the product was determined by adding various amounts of 7-hydroxycoumarin to microsomal suspension. The recovery of the product in the ether extract was about $98 \%$.

NADPH-supported metabolic conversion of 7-hydroxycoumarin to unidentified metabolite(s) was determined by measuring the decrease of 7-hydroxycoumarin in the incubation mixture. The mixture was the same as that for the above mentioned $\mathrm{O}$ dealkylase assay system, except that 7 . hydroxycoumarin (6.8 nmoles) was added as the substrate instead of 7 -alkoxycoumarin. The activity of 7-hydroxycoumarin- glucuronide formation by microsomes was monitored by determining the decrease of 7-hydroxycoumarin in a reaction mixture which consisted of microsomes, 0.27 umoles 7 -hydroxycoumarin, and $1 \mathrm{mg}$ UDPGA in $1 \mathrm{ml}$ of the buffer mixture. The reaction was started by adding microsomes and the mixture was incubated at $37^{\circ} \mathrm{C}$ for $10 \mathrm{~min}$. After termination of the reaction by immersing the tubes in a boiling water bath, the free form of 7-hydroxycoumarin in the mixture was analyzed as described above.

For product identification, the above mentioned incubation mixture for the $\mathrm{O}$ dealkylase assay system was incubated at $37^{\circ} \mathrm{C}$ for $10-20 \mathrm{~min}$, and the mixture was then extracted with $4 \mathrm{ml}$ of ether. Precoated thin layer plates (silica gel 60 F-254. Merck) were used for the separation of etherextractable products. The solvent system employed was chloroform-methanol (10:1. $v / v)$, and detection of metabolites on the plate was carried out using a Toshiba UVlight, Model Fl-3L (365 nm).

Synthesis of 7-alkoxycoumarin: The 0 methyl-, O-ethyl-, O-propyl- and O-butylderivatives of 7-hydroxycoumarin were synthesized using the corresponding atkyl iodides essentially as described previously (16). 7-Hydroxycoumarin and alkyl iodides in potassium hydroxide-containing methanol were left at room temperature for 5 days in the dark. Next the methanol was evaporated under reduced pressure, and the crystalline product was extracted using dichloromethane containing $1 \% \mathrm{KOH}$. The resulting crystalline product was washed several times with water and then recrystallized using an acetone-water system. O-Alkyl derivatives of 7-hydroxycoumarin thus obtained showed a single spot on TLC. 7-Butoxycoumarin was. however, hard to crystallize, and thus the oily product used for the experiments contained a small amount (less than 5\%) of impurities judging from TLC. Several char- 
Table 1. Characteristics of coumarin and its derivatives

\begin{tabular}{|c|c|c|c|c|c|c|c|}
\hline \multirow[b]{2}{*}{ Compound } & \multirow{2}{*}{$\stackrel{\operatorname{mip}}{\left({ }^{\circ} \mathrm{C}\right)}$} & \multicolumn{2}{|c|}{ Absorption } & \multicolumn{3}{|c|}{ Fluorescence } & \multirow{2}{*}{ Reference } \\
\hline & & $\lambda_{\max }$ & $\left(\mathrm{mM}^{-1} \mathrm{~cm}^{-1}\right)$ & $\lambda \times x$ & iet!l & $\begin{array}{l}\text { Relative } \\
\text { intensity }\end{array}$ & \\
\hline Coumarin & $68-70$ & $273.307-309$ & - & -- & - & $\ldots$ & (30) \\
\hline \multirow[t]{2}{*}{ 7-Hydroxycoumarin } & $225-228$ & 324 & - & - & - & - & (31) \\
\hline & _ & 366 & 19.3 & 370 & 455 & 100.0 & This report \\
\hline 7- Methoxycoumarin & $111-112$ & $322-323$ & 16.0 & 330 & 393 & 12.4 & This report \\
\hline 7. Ethoxycoumarin & $87-88$ & $323-324$ & 16.3 & 330 & 394 & 15.1 & This report \\
\hline 7.Propoxycoumarin & $60-61$ & $323-324$ & 17.3 & 330 & 395 & 15.9 & This report \\
\hline 7-Butoxycoumarin & oil & $323-324$ & - & - & - & - & This report \\
\hline
\end{tabular}

Absorption and fluorescence spectra of the compounds were obtained in $0.2 \mathrm{M}$ carbonatebicarbonate buffer ( $\mathrm{pH} 10)$. Relative fluorescence intensity was calculated from the fluorescence intensity observed at the optimum excitation $\left(\dot{A}_{x}\right)$ and emission $\left(\dot{\lambda}_{+m i}\right)$ wavelengths for each compound. When the intensity was compared using excitation and emission wavelengths of 370 and $455 \mathrm{~nm}$. respectively, the fluorescence intensity ratio of 7-hydroxycoumarin to 7-methoxycoumarin was about 1.500:1. 7-Hydroxycoumarin exhibited a peak ( $j_{m x}$ ) at $324 \mathrm{~nm}$ in neutral medium.

acteristics of 7-alkoxycoumarin thus synthesized are shown in Table 1. Although 7-hydroxy-and 7-alkoxy-coumarins did not differ in the absorption peak position, a remarkable difference was found in the fluorescence properties. Both excitation and emission wavelengths of 7 -hydroxycoumarin appeared at long wavelengths compared to that of 7-alkoxycoumarin. while a strong fluorescence intensity was obtained with 7 hydroxycoumarin (Table 1).

Chemicals: NAD(P)H, NADP. glucose 6phosphate and glucose 6-phosphate dehydrogenase were purchased from the Oriental Yeast Co. (Tokyo); UDPGA and B-glucuronidase, from Sigma Chemical Co. (St. Louis, Mo) and 7-hydroxycoumarin. from Nakarai Chemicals (Osaka). Other chemicals of the highest quality available were obtained commercially and used without further purification.

\section{RESULTS}

Metabolism of 7-alkoxycoumarin by liver microsomes: The in vivo metabolic fate of 7-methoxycoumarin in rats and rabbits has been studied by several investigators who found that it is extensively metabolized to 7-hydroxycoumarin, then to conjugates of glucuronic and/or sulfuric acid (25-27). Furthermore, the $\mathrm{O}$-deethylation reaction of 7-ethoxycoumarin was demonstrated to be a cytochrome P-450-dependent monooxvgenation reaction (16-24). We have studied the metabolism of 7-methoxy and 7-hydroxycoumarins using rat liver microsomes. Incubation of 7-methoxy- or 7 hydroxycoumarin with microsomes alone gave only the starting material, and not metabolite(s). The formation of 7-hydroxycoumarin from 7-methoxycoumarin was observed in the reaction mixture containing every component required for microsomal mixed-function oxidation reaction (complete system in Table 2); and when microsomes, NADPH-generating system or molecular oxygen was lacking, only 7 -methoxycoumarin resulted (Fig. $1 \mathrm{~A}$ and Table 2 ). Although Greenlee and Poland identified only 7 hydroxycoumarin using TLC as the fluorescent metabolite of the reaction (21), a thin-layer chromatogram of the ether-extract of the incubation mixture in the complete system clearly showed four fluorescent bands (Fig. 1A). Fluorescent compounds in band $d\left(R_{r}\right.$. 0.62-0.65: fluorescent color, purple) and 
Table 2. Cofactor requirements for oxidative metabolism of 7-methoxy-and 7-hydroxycoumarins by liver microsomes

\begin{tabular}{|c|c|c|c|c|}
\hline Exptl & & Gas & \multicolumn{2}{|c|}{$\begin{array}{l}\text { Fluorescence intensity } \\
\text { (arbitrary unit) }\end{array}$} \\
\hline group & & Phase & $\begin{array}{l}\text { Metabolism of } \\
\text { 7-Met-O-coumarin }\end{array}$ & $\begin{array}{l}\text { Metabolism of } \\
7-\mathrm{OH} \text {-coumarin }\end{array}$ \\
\hline \multirow[t]{4}{*}{ I } & Complete & Air & 57 & 5 \\
\hline & -NADPH-generating system & Air & 1 & 1 \\
\hline & -Substrate & Air & 0 & - \\
\hline & -Microsome & Air & 1 & 1 \\
\hline \multirow[t]{2}{*}{ II } & Complete & Air & 54 & 5 \\
\hline & Complete & N2 & 1 & 0 \\
\hline
\end{tabular}

Experiments of 7-methoxy-(7-Met-O-) and 7-hydroxy- $(7-\mathrm{OH}$-) coumarin metabolisms in the complete system of Exptl group I were caried out as described in METHODS. After 10 -min incubation at $37^{\circ} \mathrm{C}, 7$-hydroxycoumarin in the reaction mixture was determined fluorometrically (hn, $370 \mathrm{~nm}$; $\mathrm{hm}, 455 \mathrm{~nm}$ ). Liver microsomes (1 mg protein) obtained from intact rats were added to the mixture. The metabolic activities of 7 -methoxy- and 7-hydroxycoumarins are expressed in the table as the increase and decrease, respectively. of the fluorescence intensity. Experiments in Exptl group II were performed using Thumberg tubes. In the main compartment was placed $2.1 \mathrm{ml}$ of the buffer mixture containing $2 \mathrm{mg}$ protein of microsomes and substrate $(1.14$ umoles 7 -methoxycoumarin or 6.8 nmoles 7 . hydroxycoumarin), and in the side-arm was placed $0.9 \mathrm{ml}$ of the buffer mixture containing 1 :"mole NADP, 10, imoles glucose 6 -phosphate and $2.5 \mathrm{I}$.U. glucose 6 -phosphate dehydrogenase. The gas phase described was achieved by repeated evacuation and filling. The reaction was started by mixing the contents and the incubation was carried out at $37^{\circ} \mathrm{C}$ for $10 \mathrm{~min}$. Under the assay conditions employed, standard 7 -hydroxycoumarin solution $(6.8$ nmol/cuvette) showed 70 units fluorescence intensity.

band $b\left(R_{r}, 0.42-0.43\right.$; fluorescent color. bluish violet) showed similar mobilities on TLC and fluorescent colors to authentic 7 . methocy-and 7-hydroxy-coumarins, respectively. In addition, two more fluorescent products (bands a and c) were detected in the incubation mixture (Fig. 1A, reaction system 1). As expected from Table 2, lack of either NADPH (reaction system 2) or microsomes (reaction system 4) produced no metabolic conversion of 7-alkoxycoumarin. NADPH was not extracted into ether from the incubation mixture (reaction system 3 ). The results shown in Fig. $1 \mathrm{~A}$ and Table 2 indicate that 7-methoxycoumarin is metabolized into at least three different products by microsomal enzymes in the presence of NADPH and molecular oxygen.

Incubation of 7-hydroxycoumarin with microsomes. NADPH and molecular oxygen resulted in a slight decrease of the fluorescent intensity of the compound, and the lack of one of these cofactors resulted in no production of the decrease in the fluorescent intensity (Table 2). A thin-layer chromatogram of the ether-extract of the incubation mixture showed the existence of unidentified metabolite(s) other than the parent compound, 7-hydroxycoumarin (Fig. 1B). The fluorescent metabolite (band $\mathrm{a}$ in Fig. 1B) showed similar mobility on TLC $\left(R_{f}, 0.23-\right.$ 0.25 ) and fluorescent color (bluish white) to the band $a$ in Fig. 1A. Lack of either NADPH (reaction system 2) or microsomes (reaction system 3) resulted in no conversion of 7-hydroxycoumarin. These results indicated the metabolic conversion of 7-hydroxycoumarin to unidentified compound(s) by microsomat enzymes in the presence of NADPH and molecular oxygen as cofactors. 
(A)

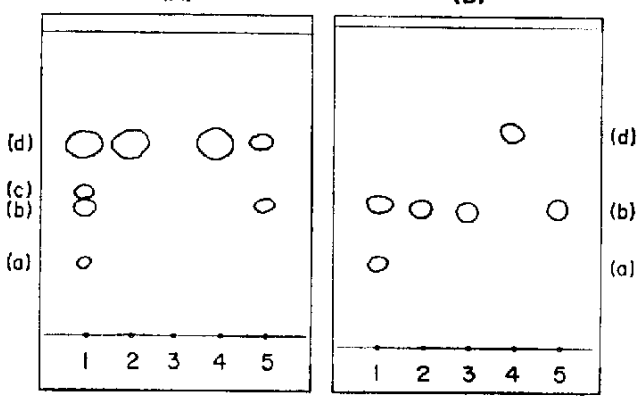

Fig. 1. Thin-layer chromatogram of the metabolites after incubation of 7-methoxy- and 7-hydroxycoumarins with rat liver microsomes. (A) TLC pattern of ether-extractable metabolites of 7 methoxycoumarin: System 1, Complete reaction system for $\mathrm{O}$-dealkylase assay as described in METHODS. Liver microsomes (1.44 mg protein) prepared from intact rats were used and incubation was performed at $37^{\circ} \mathrm{C}$ for $10 \mathrm{~min}$ : System 2. NADPH was omitted from the incubation mixture: System 3, 7-Methoxycoumarin was omitted: System 4. Microsomes were omitted: System 5, Reference samples of 7-methoxy- and 7-hydroxy-coumarins. (B) TLC pattern of ether-extractable metabolites of 7-hydroxycoumarin: System 1, Complete reaction system as described in METHODS. Reaction was carried out at $37^{\circ} \mathrm{C}$ for $20 \mathrm{~min}$ : System 2. NADPH was omitted: System 3. Microsomes were omitted: System 4. Reference sample of 7-methoxycoumarin; System 5 . Reference sample of 7-hydroxycoumarin.

and the compound at band a on the chromatogram was supposedly the second metabolic product of 7-methoxycoumarin.

Incubation of 7-hydroxycoumarin with microsomes and UDPGA also resulted in a decrease of the fluorescent intensity of 7 . hydroxycoumarin in the incubation mixture. After termination of the reaction by heat treatment, $2 \mathrm{mg}$ of $\beta$-glucuronidase was added to the incubation tube, and the mixture was incubated again for $1 \mathrm{hr}$ at $37^{\circ} \mathrm{C}$. No decrease of the fluorescent intensity of 7-hydroxycoumarin was observed in the resulting mixture, indicating that 7-hydroxycoumarin is metabolized by microsomal enzyme to non-fluorescent glucuronide (25) in the presence of a cofactor, UDPGA. The above results lead to the conclusion that 7 . hydroxycoumarin is one of the metabolites of 7-alkoxycoumarin, and it is further metabolized to unidentified metabolite(s) and/or glucuronide by microsomal enzymes (Fig. 2).

Assay conditions of 7-alkoxycoumarin 0 dealkylase activity: As shown above, microsomal enzyme(s) metabolize 7-alkoxycoumarin to 7-hydroxycoumarin (band b in Fig. 1), then to unidentified metabolite(s) (band a in Fig. 1) in the presence of NADPH and molecular oxygen. However, the latter reaction is so slow that the $\mathrm{O}$-dealkylase activity of 7-alkoxycoumarin can be determined apparently by measuring the amount of 7-hydroxycoumarin produced. Another metabolite (band $c$ in Fig. 1) had a similar fluorescent property to the parent compound. indicating that the determination of 7 . hydroxycoumarin in the ether-extract of the incubation mixture is possible without interferences from the parent compound and other metabolites. However, since 7 alkoxycoumarin had a weak fluorescence under the assay conditions of 7-hydroxycoumarin (Table 2), a NADPH-free incubation mixture was used as a blank sample.

The optimum assay conditions for microsomal 7-alkoxycoumain 0 -dealkylase were studied using 7-methoxycoumarin as a model substrate. The time course of the O-dealkylation by rat liver microsomes was linear for $10 \mathrm{~min}$, and the amount of 7 . hydroxycoumarin formed was directly proportional to the amount of microsomes from O-2 mg protein $/ 1.5 \mathrm{ml}$ of the incubation mixture. Maximal activity of the $\mathrm{O}$ dealkylation of 7-methoxycoumarin showed an absolute requirement for NADPH and molecular oxygen (Table 2). The $\mathrm{O}$ dealkylation reaction was also observed by the use of NADH as the electron donor, but 
the activity was very small compared to that of the NADPH-dependent reaction. Therefore, the assay procedure of microsomal alkoxycoumarin $\mathrm{O}$-dealkylase activity. finally established from the above results, is as described in METHODS. Using same microsomal preparations, the O-dealkylase activity determined by this method was compared to the one obtained by the aforementioned methods (19. 21). No difference in the activity was obtained between these assay methods.

Substrate specificity of microsomal 7 . alkoxycoumarin $\mathrm{O}$-dealkylase: Microsomal $O$-dealkylase activity was determined using the O-methyl-, O-ethyl-. O-propyl-and $\mathrm{O}$ butyl-derivatives of 7-hydroxycoumarin as substrates. The highest activity was observed when 7-ethoxycoumarin was employed as substrate, and the activities decreased when either the O-propyl or $\mathrm{O}$ butyl group was substituted as the O-alkyl group. Pretreatment of animals with phenobarbital resulted in a marked increase of the O-dealkylase activity for all 7-alkoxy coumarins tested, but the ratios of $\mathrm{O}$ deethylase. $\mathrm{O}$-depropylase and $\mathrm{O}$-debutylase activities to $\mathrm{O}$-demethylase activity were not altered markedly by this pretreatment (Table 3). Pretreatment of animals with 3 -methylcholanthrene or $\beta$-naphthoflavone produced a marked increase in microsomal 0 . deethylase, $\mathrm{O}$-depropylase and $\mathrm{O}$-debutylase activities, while $\mathrm{O}$-demethylase activity showed a slight decrease in these microsomes. The ratios of $\mathrm{O}$-deethylase. O-depropylase and $\mathrm{O}$-debutylase activities to $\mathrm{O}$-demethylase activity increased remarkably in liver microsomes from 3-methylcholanthrene or $\beta$ naphthoflavone-pretreated rats. Similar results were obtained using microsomes prepared from female rats (Table 3). The results shown in Table 3 are similar to those reported by Kamataki et al. (24). These results lead to the conclusion that cyto- chrome P-450's localized in intact and phenobarbital-pretreated rats catalyze the O-dealkylation reaction of all the O-alkyl derivatives of 7-hydroxycoumarin tested at a similar rate. Whereas cytochrome P-448 induced by the administration of 3-methylcholanthrene or $\beta$-naphthoflavone preferentially catalyzes the conversion of O-ethyl. O-propyl and O-butyl derivatives of 7 hydroxycoumarin, but not the O-methyl derivative.

To confirm the relationship between molecular species of cytochrome P.450 and the substrate-specificity of 7-alkoxycoumarin 0 -dealkylase, effects of $\alpha$-naphthoflavone and hexobarbital were studied using liver microsomes from animals in various states. As described by Kamataki et al. (24) the O-dealkylase activities, especially $\mathrm{O}$ deethylase and $\mathrm{O}$-depropylase activities in $\beta$-maphthoflavone-pretreated rat microsomes were inhibited markedly by $\alpha$-naphthoflavone, a specific inhibitor of microsomal cytochrome P.448-dependent hydroxylation reactions (32). On the other hand, the O-dealkylase activities in intact and phenobarbitalpretreated rats were not only inhibited by this inhibitor but stimulation of the activity was observed in the 7-ethoxycoumarin $\mathrm{O}$ deethylase system (data not shown). The results probably indicate that cytochrome P-448 catalyzes the $\mathrm{O}$-dealkylation reaction of O-ethyl and 0-propyl derivatives of 7 hydroxycoumarin, which is consistent with the remarkable increase of $\mathrm{O}$-deethylase, $\mathrm{O}$ depropylase and $\mathrm{O}$-debutylase activities in microsomes obtained from 3-methylcholanthrene- or $\beta$-naphthoflavone-pretreated rats (Table 3 ).

On the contrary, the $\mathrm{O}$-dealkylase activities in liver microsomes obtained from intact and phenobarbital-pretreated rats were inhibited remarkably by the addition of the type I substrate, hexobarbital (33), to the reaction mixture, while the activities in ,3-naph- 


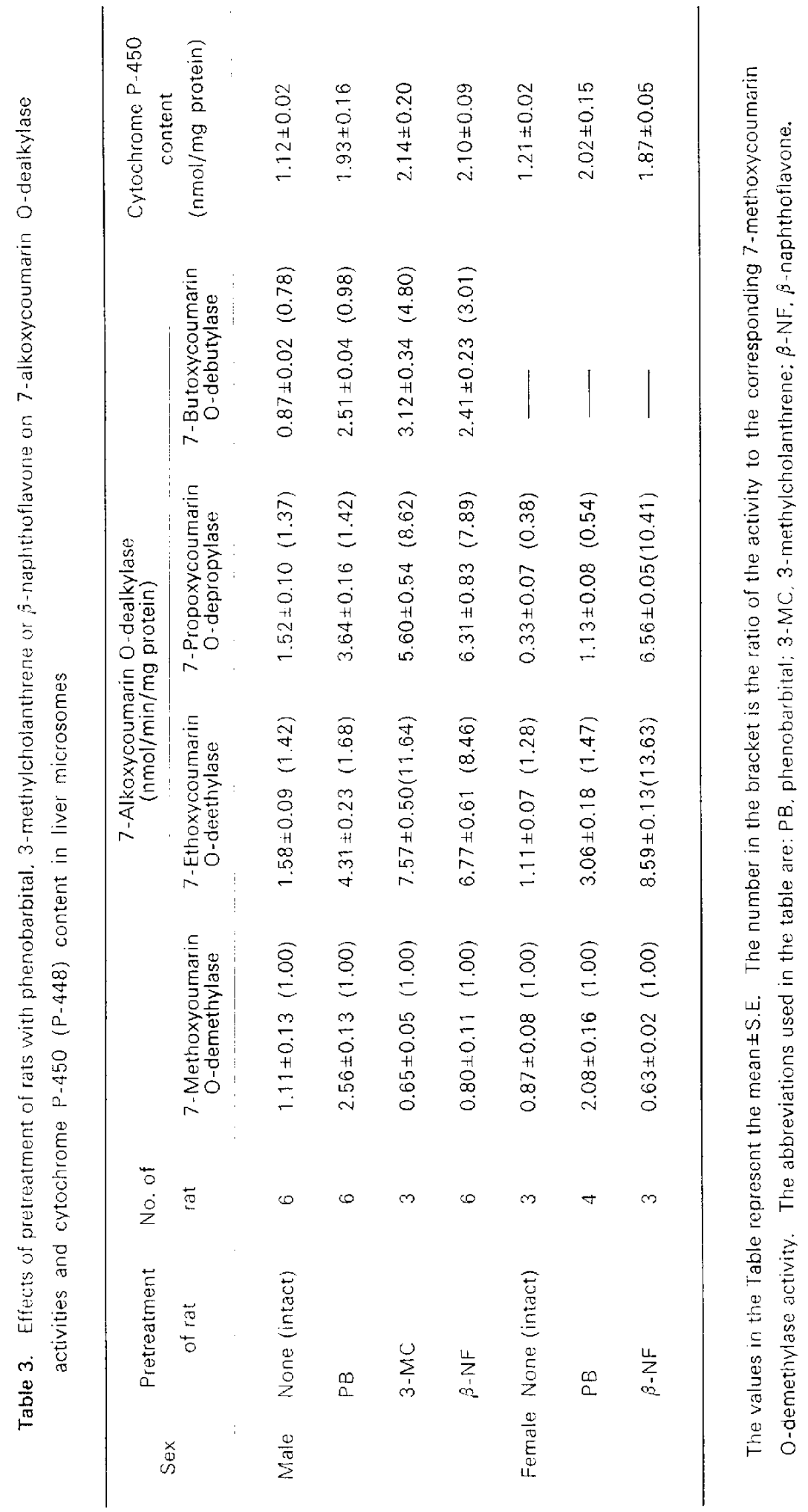


thoflavone-pretreated rat microsomes were less sensitive to hexobarbital (data not shown). The results suggest that one (or more) species of cytochrome P-450's, interacting specifically with hexobarbital. catalyze the $\mathrm{O}$-dealkylation reaction in intact and phenobarbital-pretreated rats, and the cytochrome is probably different from $\beta$ naphthoflavone-inducible cytochrome $P$ 448.

Species differences in microsomal 7 alkoxycoumarin $\mathrm{O}$-dealkylase: Since marked species differences in drug metabolism have become evident from data obtained by many investigators, it was decided to determine the O-dealkylation activity of 7 -alkoxycoumarin using liver microsomes obtained from various species of animals. As observed in rat liver microsomes (Table 3), changing the alkyl group from a methyl- to a propyl-group resulted in marked alterations in the $\mathrm{O}$ dealkylase activities in all microsomes tested (Table 4). Liver microsomes obtained from mice, rabbits and dogs showed almost similar values in the specific activities of $\mathrm{O}$-demethylation and $\mathrm{O}$-deethylation reactions, and the $\mathrm{O}$-depropylation activity showed very low activity. On the other hand, the $\mathrm{O}$-demethylation reaction showed the highest activity in liver microsomes obtained from guinea pigs and monkeys, and changing the methyl group to ethyl- and propyl-groups resulted in gradual decrease of the activity (Table 4).

Correlation of the 0 -dealkylase system to other microsomal drug-metabolizing enzyme system: As shown in Fig. 2, microsomal drug-metabolizing enzymes catalyze the conversions from 7-alkoxycoumarin to 7 hydroxycoumarin (reaction step 1) and from 7 -hydroxycoumarin to unidentified metabolite(s) (reaction step 2) and/or to form a conjugate with glucuronic acid (reaction step 3). Since the 7-alkoxycoumarin 0 dealkylase activity (reaction step 1) was altered remarkably by pretreatment of animals with typical inducers and changing the $\mathrm{O}$-alkyl substituent of 7 -alkoxycoumarin (Table 3). we checked the effects of pretreating the animals with typical inducers on every reaction step of the 7-alkoxycoumarin metabolizing system in microsomes. As indicated in Table 3. 7-methoxycoumarin O-demethylase activity was stimulated markedly by the pretreatment of rats with phenobarbital, but

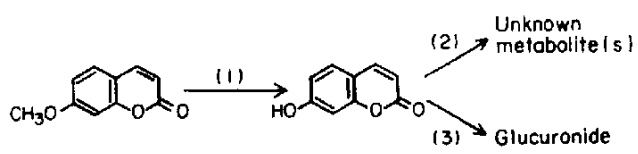

Fig. 2. Metabolism of 7-alkoxycoumarin by microsomal enzymes.

Table 4. Species differences in liver microsomal 7-alkoxycoumarin 0 -dealkylase activity

\begin{tabular}{|c|c|c|c|c|c|}
\hline Animal & Number of & \multicolumn{3}{|c|}{$\begin{array}{l}\text { 7-Alkoxycoumarin o-dealkylase } \\
(\mathrm{nmol} / \mathrm{min} / \mathrm{mg} \text { protein) }\end{array}$} & $\begin{array}{c}\text { Cytochrome } \\
\text { P.450 }\end{array}$ \\
\hline species & animals & $\begin{array}{l}\text { 7-Methoxy- } \\
\text { coumarin }\end{array}$ & $\begin{array}{l}\text { 7-Ethoxy- } \\
\text { coumarin }\end{array}$ & $\begin{array}{l}\text { 7-Propoxy- } \\
\text { coumarin }\end{array}$ & $\begin{array}{l}\text { content } \\
\text { (nmol/mg } \\
\text { protein) }\end{array}$ \\
\hline Mouse & $20^{*}$ & $1.87 \pm 0.30(1.00)$ & $1.99 \pm 0.27(1.06)$ & $0.61 \pm 0.06 \quad(0.33)$ & $1.87 \pm 0.22$ \\
\hline Guinea pig & 4 & $2.44 \div 0.32(1.00)$ & $1.69 \pm 0.22(0.69)$ & $0.84 \pm 0.18 \quad(0.34)$ & $1.83 \pm 0.12$ \\
\hline Rabbit & 4 & $1.44 \pm 0.31 \quad(1.00)$ & $1.56 \pm 0.27(1.08)$ & $0.78 \pm 0.15 \quad(0.54)$ & $1.73 \pm 0.16$ \\
\hline Dog & 6 & $7.15 \pm 0.17(1.00)$ & $1.60 \pm 0.22 \quad(1.39)$ & $0.34 \pm 0.04 \quad(0.30)$ & $0.90 \pm 0.05$ \\
\hline Monkey & 4 & $3.53 \pm 0.15(1.00)$ & $2.70 \pm 0.05 \quad(0.76)$ & $0.61 \pm 0.07 \quad(0.17)$ & $1.72 \pm 0.28$ \\
\hline
\end{tabular}

Liver microsomes obtained from adult male animals were used for the $O$-dealkylase assay. The values in the table represent the meant \pm .E., and the number in the bracket is the ratio of the activity to the corresponding 7 -methoxycoumarin O-demethylase activity. *Pooled livers from 5 mice were used for the preparation of microsomes. 
Table 5. Effect of pretreatment of animals with phenobarbital and $\hat{j}$-naphthoflavone on in vitro metabolism of 7 -methoxy-and 7 -hydroxy-coumarins by rat liver microsomes

\begin{tabular}{ccccc}
$\begin{array}{c}\text { Pretreatment } \\
\text { of animal }\end{array}$ & $\begin{array}{c}\text { Number } \\
\text { of rat }\end{array}$ & $\begin{array}{c}\text { Activity (nmol/min/mg protein) } \\
\text { Reaction } \\
\text { step (1) }\end{array}$ & $\begin{array}{c}\text { Reaction } \\
\text { step (2) }\end{array}$ & $\begin{array}{c}\text { Reaction } \\
\text { step (3) }\end{array}$ \\
Vone (intact) & 3 & $0.95 \pm 0.09$ & $0.05 \pm 0.01$ & $1.98 \pm 0.13$ \\
Phenobarbital & 5 & $2.08 \pm 0.12$ & $0.26 \pm 0.02$ & $7.11 \pm 0.60$ \\
S-Naphthoflavone & 4 & $0.83 \pm 0.05$ & $0.05 \pm 0.02$ & $11.35 \pm 0.96$ \\
\hline
\end{tabular}

Specific activities of reaction step (1) and reaction steps (2) and (3) are exprossed as " $n m$ mol 7-hydroxycoumarin produced/min/mg protein" and "nmol 7-hydroxycoumarin decreased/ min/mg protein", respectively. The values in the table represent the mean \pm S.E.

not with 3-naphthoflavone (Table 3). Similarly, the metabolic conversion of 7 . hydroxycoumarin to unidentified metabolite(s) (reaction step 2) increased with the administration of phenobarbital to rats, but the conversion was not altered by the pretreatment of animals with , 3-naphthoflavone. The rate of the step 2 reaction was very slow even after pretreatment of rats with phenobarbital. Conjugate formation between 7 -hydroxycoumarin and glucuronic acid (reaction step 3) was, on the other hand, stimulated markedly by the pretreatment of rats with is-naphthoflavone. Pretreatment of animals with phenobarbital also stimulated glucuronide formation of 7 -hydroxycoumarin. but to a less extent than that of $\beta$-naphthoflavone-pretreatment (Table 5).

Both O-dealkylase and UDP-glucuronyltransferase are supposed to organize functionally in the endoplasmic reticulum of hepatocytes. Thus, the NADPH-supported metabolism of 7 methoxycoumarin by microsomal enzymes was studied in the presence or absence of UDPGA. The time course of 7-hydroxycoumarin production from 7 methoxycoumarin was linear for about $10 \mathrm{~min}$ under the experimental conditions, and then the activity declined gradually with time. When UDPGA was further added to the incubation mixture, the apparent 7-hydroxycoumarin production was depressed by about $10 \%$. After a 10-min incubation of micro. somes with substrate. NADPH and UDPGA under aerobic conditions, the reaction was terminated by heat treatment. and then a small amount of $\beta$-glucuronidase was added to the reaction mixture. The resulting mixture was further incubated at $37^{\circ} \mathrm{C}$ for $1 \mathrm{hr}$, and afterwards the amount of 7 -hydroxycoumarin in the reaction mixture was determined. The reduced amount of 7-hydroxycoumarin due to addition of UDPGA was recovered completely to the control level by this treatment, indicating that 7-hydroxycoumarin produced from 7-methoxycoumarin by the 0 -demethylation reaction is further metabolized to a conjugate with glucuronic acid in the presence of UDPGA.

\section{DISCUSSION}

The in vivo metabolic fate of herniarin (7-methoxycoumarin) in rats has been investigated by Indahl and Schleline who identified demethylated. hydroxylated and lactone-ring cleavage products, and also their conjugates as urinary metabolites (27). Tho results suggest, as one of the metabolic routes, that 7 -alkoxycoumarin is converted to 7 -hydroxycoumarin, then to its conjugate with glucuronic acid. In the present investigation, we demonstrated a similar metabolic fate for 7-alkoxycoumarin with microsomal enzymes in the presence of NADPH, molecular oxygen and UDPGA as cofactors (Table 2 and F, , 1). In atdition. 
several metabolites were detected in the assay medium for 7 -alkoxycoumarin $\mathrm{O}$ dealkylase by TLC (Fig. 1), although Greenlee and Poland could not detect fluorescent metabolite(s) other than 7-hydroxycoumarin (21). We could also detect several metabolites in the chloroform-extract of the assay medium, even by the method of Greenlee and Poland (21). These results indicate that metabolic reactions other than the $\mathrm{O}$ dealkylation may be proceed simultaneousiy. The product resulting from this reaction (band $\mathrm{C}$ in Fig. 1), as suggested from its mobility on TLC and its fiuorescent color. is a hydroxylated, but not dealkylated compound. The dealkylated metabolite. 7 hydroxycoumarin, is demonstrated to be metabolized further to an unidentified metabolite(s) by microsomal enzymes in the presence of NADPH and $\mathrm{O}_{2}$ (band a in Fig. 1). Indahl and Schel!ne identified 3.7-dihydroxycoumarin as the urinary metabolite in rats administered 7 -hydroxycoumarin (27). The result suggests that the unidentified metabolite (band a) produced in the microsomal assay system is dihydroxycoumarin. interestingly, metabolic conversion of 7 . hydroxycoumarin to unidentified metabolite(s) is only stimulated by the pretreatment of animals with phenobarbital (Table 5). On the other hand, glucuronide formation from 7-hydroxycoumarin was stimulated by the pretreatment of rats with, 3 -naphthoflavone, rather than with phenobarbital (Table 5). indicating that the enzymes participating in the metabolism of 7 -hydroxycoumarin are regulated differently with different inducers. Further studies must be done to clarify the regulatory mechanisms.

The cofactor requirements (Table 2) and the NAD(P)H-dependency of microsomal 7 -alkoxycoumarin $\mathrm{O}$-dealkylase indicate, as pointed out by Ullich and Weber (16), that the reaction is catalyzed by cytochrome $P-450$. The existence of multiple forms of cytochrome P-450 has been established in liver microsomes obtained from various species of animals, and these hemoproteins have been shown to have different substrate specificities (8. 9, 35-38). Cytochrome $\mathrm{P}-448$, induced by the pretreatment of animals with 3-methylcholanthrene or isnaphthoflavone, is known to preferentially metabolize benzo(a)pyrene or polycyclic hydrocarbons, particularly carcinogenic compounds, and the increase of cytochrome P-448 in liver microsomes is detectable by measuring the aryl hydrocarbon hydroxylase activity. as well as by the spectroscopic determination of this cytochrome. Liver microsomes obtained from 3-methyicholanthrene- or $\beta$-naphthoflavone-pretreated rats showed very high activity in the 0 . dealkylation reaction of O-ethyl, O-propyl and O-butyl derivatives of 7 -hydroxycoumarin, but not of the 0 -methyl derivative (Table 3). suggesting that the ratio of $\mathrm{O}$-deethylase. $\mathrm{O}$-depropylase or O-debutylase activity to that of $\mathrm{O}$-demethylase approximately indicates the alterations of the cytochrome P-450 species in microsomal membranes. On the other hand, liver microsomes obtained from phenobarbital pretreated rats showed a remarkable increase in the specific activity of the 0 -dealkylation reaction for all the substrates tested, but the ratio of $\mathrm{O}$-deethylase, O-depropylase or O-debutylase activity to that of $\mathrm{O}$-demethylase was almost similar to that in intact rats (Table 3 ). The results probably indicate that the microsomal cytochrome P.450 inducible by phenobarbital pretreatment has the same substrate specificity as the cytochrome in intact rat microsomes. Therefore, the metnod for measuring 7-alkoxycoumarin O-dealkylase activity and comparing their substrate specificity is applicable for routine determination of the composition or molecular species of cytochrome P-450's and is very beneficial since it does not require the use of dangerous 
carcinogenic compound for the assay.

Species differences in drug metabolism is well established, and the differences are observed qualitatively or quantitatively depending on drug employed. In the case of the 7 -alkoxycoumarin 0 -dealkylation reaction, species differences were also detected as shown in Table 4. Levin et al. reported the purification of cytochrome P-450 and P-448 from various species of animals, which had different catalytic. spectral, and immunological properties (9). It is thus interesting to clarify the relationship between species differences in the $\mathrm{O}$-dealkylation reaction and molecular species of cytochrome P-450 in different animals. Further studies along this line are progress in our laboratory and will be reported elsewhere.

\section{REFERENCES}

1) Estabrook, R.W.: Cytochrome P.450. Its function in the oxidative metabolism of drugs. in Handbuch der Experimentallen Pharmakologie. Edited by Brodie, B.B. and Gillette, J., Vol. 27. Part 2, p. 264-284, Springer-Verlag, Berlin (1971)

2) Gillette, J.R., Davis, D.C. and Sasame, H.A.: Cytochrome $P .450$ and its role in drug metabolism. A. Rev. Phiarmacol. 12, 57-84 (1972)

3) Gillette, J.R.: Effects of induction of cytochrome P.450 enzymes on the concentration of foreign compounds and their metabolites and on the toxicological effects of these compounds. Drug Metab. Rev. 10, 59-87 (1979)

4) Lu, A.Y.H., West, S.B., Ryan, D. and Levin, W.: Characterization of partially purificd cytochrome P. 450 and P.448 from rat liver microsomes. Drug Metab. Dispos. 1, 29-39 (1973)

5) Imai, $Y$. and Sato, R.: A gel-electrophoretically homogeneous preparation of cytochrome P-450 from liver microsomes of phenobarbital-pretreated rabbits. Biochem. biophys, Res. Commun. 60, 8-14 (1974)

6) Hashimoto, C. and Imai, Y.: Purification of a substrate complex of cytochrome P-450 from liver microsomes of 3-methylcholanthrenetreated rabbits. Biochem. biophys. Res. Commun. 68, 821-827(1976)

7) Guengerich, F.P.: Separation and purification of multiple forms of microsomal cytochrome
P.450. J. biol. Chem. 253, 7931-7939 (1978)

8) Coon, M.J., Ballow, D.P., Haugen, D.A., Krezoshi, S.O., Nordblom, G.D. and White, R.E.: Purification of membrane-bound oxygenases: Isolation of two electrophoretically homogeneous forms of liver microsomal cytochrome P.450. In Microsomes and Drug Oxidations, Edited by Ullich, V., Roots, I. Hildebrandt. A. Estabrook. R.W. and Conney. A.H., p. 82-94, Pergamon Press, Oxford (1977)

9) Levin, W., Ryan, D., Huang, W.T., Kawalek, J., Thomas, P.E., West, S.B. and Lu, A.Y.H.: Characterization of multiple forms of highly purified cytochrome P-450 from the liver microsomes of rats, mice and rabbits. in Microsomes and Drug Oxidations, Edited by Ullich. V., Roots, 1., Hildebrandt, A.. Estabrook, R.W. and Conney, A.H., p. 185-191, Pergamon Press, Oxford (1977)

10) Norman, R.L., Johnson, E.F. and MullerEberhard, U.: Identification of the major cytochrome P-450 from trans-placentally induced in neonatal rabbits by $2,3.7 .8$ tetrachlorodibenzo-p-dioxin. J. biol. Chem. 253, 8640-8647 (1978)

11) Gelboin, H.V., Wiebel, F.J. and Kinoshita, N.: Microsomal aryl hydrocarbon hydroxylases: On their role in polycyclic hydrocarbon carcinogenesis and toxicity and the mechanism of enzyme induction. In Biological Hydroxylation Mechanisms, Edited by Boyd, G.S. and Smellie, M.S. p. 103-133. Academic Press, New York (1972)

12) Lu, A.Y.H., Levin, W., West, S., Jacobson, M., Ryan, D., Kuntzman, R. and Conney, A.H.: The role of cytochromes $P-450$ and $P-448$ in drug and steroid hydroxylations. Ann. N.Y. Acad. Sci. 212, 156-174 (1973)

13) Nebert, D.W., Considine, $N$. and Kon, $H$.: Genetic differences in cytochrome P-450 during induction of monooxygenase activities. Drug Metab. Dispos. 1, 251-258 (1973)

14) Werringloer, J. and Estabrook, R.W.: The characterization of product adducts of liver microsomal cytochrome P-450 and their use as probes for the heterogeneity of cytochrome P-450 as modified by the induction of drug metabolism. In The Induction of Drug Metabolism. Edited by Estabrook. R.W. and Lindenlaub. E. p. 269-307, F.K. Schattauer. Stuttgart (1979)

15) Gillette, J.R.: Toxicological implication of drug metabolism. In The Induction of Drug Metabolism. Edited by Estabrook. R.W. and Lindenlaub. E., p. 309-325. F.K. Schattauer, Stuttgart (1979)

16) Ullrich, $V$. and Weber, P.: The $O$-dealkylation of 7-ethoxycoumarin by liver microsomes: A 
direct fluorometric test. Hoppe-Seyler's Z. physiol. Chem. 353, 514-520 (1973)

17) Ulirich, V., Frommer, U. and Weber, P.: Differences in the $\mathrm{O}$-dealkylation of 7-ethoxycoumarin after pretreatment with 3-methylcholanthrene. Hoppe-Seyler's Z. physiol. Chem. 354, 514-520 (1973)

18) Lehrmann, Ch., Ullrich, V. and Rummel, W.: Phenobarbital inducible drug monooxygenase activity in the small intestine of mice. NaunynSchmiedeberg's Arch. Pharmacol. 276, 89-98 (1973)

19) Jacobson, M., Levin, W., Poppers, P.J., Wood, A.W. and Conney, A.H.: Comparison of the 0 -deethylation of 7-ethoxycoumarin and the hydroxylation of benzo(a)pyrene in human placenta. Clin. Pharmacol. Ther. 16, 701-710 (1974)

20) Kapitulnik, J., Popper, P.J. and Conney, A.H.: Comparative metabolism of benzo(a)pyrene and drugs in human liver. Clin. Pharmacol. Ther. 21. 166-176 (1977)

21) Greenlee, W.F. and Poland, A.: An improved assay of 7-ethoxycoumarin 0 -deethylase activity: Induction of hepatic enzyme activity in $\mathrm{C}_{57} \mathrm{BL} / 6 \mathrm{~J}$ and $\mathrm{DBA} / 2 \mathrm{~J}$ mice by phenobarbital, 3-methylcholanthrene and 2,3.7.8tetrachlorodibenzo-p-dioxin. J. Pharmacol. exp. Ther. 205, 596-605 (1978)

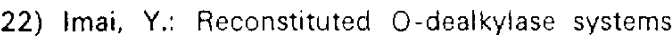
containing various forms of liver microsomal cytochrome P-450. J. Biochem., Tokyo, 86, 1697-1707 (1979)

23) A!-Turk, W.A., Stohs, S.J. and Roche, E.B.: Altered metabolism of 7-ethoxycoumarin by hepatic, pulmonary and intestinal microsomes from streptozotocin-diabetic rats. Drug Metab. Dispos. 8, 44-45 (1980)

24) Kamataki, T., Ando, M., Yamazoe, Y., Ishii, K. and Kato, R.: Sex differences in the O-dealkylation activity of 7-hydroxycoumarin 0 -alkyl derivatives in liver microsomes of rats. Biochem Pharmacol. 29, 1015-1022 (1980)

25) Mead, J.A.R., Smith, J.N. and Williams, R.T.: Studies in detoxication. 71. The metabolism of hydroxycoumarins. Biochem. J. 68, 61-67 (1958)

26) Keighen, M. and Williams, R.T.: The metabolism of $(3-14 \mathrm{C})$-coumarin. J. Med. Pharm. Chem. 3. 35-43 (1961)

27) Indahl, S.R. and Scheline, R.R.: The metabolism of umbelliferone and herniarin in rats and by the rat intestinal microflora. Xenobiotics 1 $13-24$ (1971)

28) Gornall, A.G., Bardawill, C.J. and David, M.M.: Determination of serum protein by means of the biuret reaction. J. biol. Chem. 177, 751-756 (1949)

29) Omura, T. and Sato, R.: The carbon monoxidebinding pigment of liver microsomes. I. Evidence for its hemoprotein nature. J. biol. Chem. 259, 2370-2378 (1964)

30) Ganguly, B.K. and Bagchi, P.: Studies on the ultraviolet absorption spectra of coumarin and chromones. Part I. J. org. Chem. 21, 1415-1419 (1956)

31) Sen, K. and Bagchi, P.: Studies on the ultraviolet absorption spectra of coumarin and chromones. II. Hydroxy derivatives. J. org. Chem. 24, 316-319 (1959)

32) Goujon, F.M., Nebert, D.W. and Gielen, J.E.: Genetic expression of aryl hydrocarbon hydroxylase induction. IV. Interaction of various compounds with different forms of cytochrome P-450 and the effect on benzo(a)pyrene metabolism in vitro. Mol. Pharmacol. 8,667-680 (1972)

33) Schenkman, J.B., Remmer, H. and Estabrook, R.W.: Spectral studies of drug interaction with hepatic microsomal cytochrome. Mol. Pharmacol. 3, 113-123 (1967)

34) Haugen, D.A., van der Hoeven, T.A. and Coon, M.J.: Purified liver microsomal cytochrome P.450. Separation and characterization of multiple forms. J. biol. Chem. 250, 3567-3570 (1975)

35) Huang, M.-T., West, S.B. and Lu, A.Y.H.: Separation, purification, and properties of multiple forms of cytochrome P. 450 from the liver microsomes of phenobarbital-treated mice. J. biol. Chem. 251, 4659-4665 (1976)

36) Gibson, G.G. and Schenkman, J.B.: Purification and properties of cytochrome P-450 obtained from liver microsomes of untreated rats by lauric acid affinity chromatography. J. biol. Chem. 253, 5957-5963 (1978)

37) Ryan, D.E., Thomas, P.E., Korzeniowski, D. and Levin, W.: Separation, and characterization of highly purified forms of liver microsomal cytochrome P.450 from rats treated with polychlorinated biphenyls, phenobarbital, and 3-methylcholanthrene. J. biol. Chem. 254, 1365-1374 (1979) 